\title{
Contenido y alcance del concepto de cumplimiento de las obligaciones (solutio) en derecho romano clásico*
}

\section{Paula natalia Robles Bacca*}

Resumen: el presente artículo hace un recorrido cronológico por medio de algunas de las fuentes del derecho romano que permiten establecer el origen, el contenido y el alcance del concepto de cumplimiento de las obligaciones (solutio) en Roma. Para ello, se procede a una reflexión acerca de los cambios que sufrió el término solutio entre los periodos arcaico y clásico del derecho romano, para luego centrarnos en el estudio exegético de algunas fuentes romanas que contienen referencias a solutio, solvere y satisfactio, a fin de establecer por esta vía el antecedente estructural de la actual noción de cumplimiento de las obligaciones.

Palabras clave: cumplimiento, obligación, solutio, satisfactio.

\section{The Concept of 'Due Performance' (solutio) of Civil Obligations in Classic Roman Law: Content and Scope}

Aвstract: This article displays a chronological journey of some of the sources of Roman Law that allows us to establish the concept of the "due performance"

* Fecha de recepción: I 2 de junio de 2015. Fecha de aceptación: 9 de octubre de 2016.

Para citar el artículo: P. N. Robles BACCA, "Contenido y alcance del concepto de cumplimiento de las obligaciones (solutio) en derecho romano clásico", Revista de Derecho Privado, Universidad Externado de Colombia, n. ${ }^{\circ}$ 3 I, julio-diciembre de 20I6, 55-86. Dor: http://dx.doi. org/I0.1860I/oI234366.n31.03

* Abogada de la Universidad Externado de Colombia, Bogotá, Colombia. Magíster en Sistemas Jurídicos Contemporáneos de la Università degli Studi di Roma 'Tor Vergata', Roma, Italia, y candidata a doctora en la misma Universidad. Investigadora de la Universidad Externado de Colombia, Bogotá, Colombia. Contacto: paula.robles@uexternado.edu.co 
in Rome. To this extent, we proceed to a reflection of the modifications and adjustments occurred regarding the concept of solutio, during archaic and classical Roman law. Therefore, we will focus on the exegetical study of some other Roman sources, which contains references to solutio, solvere and satisfactio, in order to establish through this path, the structural antecedent of the current notion of "due performance of obligations".

KEYworDs: Due performance, obligation, solutio, satisfactio.

Sumario: Introducción. I. Reflexiones históricas sobre la transformación de la solutio entre los periodos arcaico y clásico del derecho romano. II. La noción de cumplimiento perfilada por los juristas del periodo clásico: la pervivencia de una tradición reflejada en la duplicidad de significados que conviven al interior del término solvere. III. Contenido y alcance del término satisfactio y su relación con el problema del cumplimiento exacto en derecho romano. Conclusiones. Bibliografía.

\section{Introducción}

El presente artículo se propone exponer cuál fue el origen, así como también el contenido y alcance del concepto de cumplimiento de las obligaciones (solutio) en derecho romano clásico.

Es importante explicar desde ahora que el cumplimiento de las obligaciones como categoría contemporánea puede subsumirse, aunque no perfectamente, en el término latino solutio, razón por la cual el presente trabajo está dedicado a analizar el desarrollo de este concepto en la jurisprudencia clásica romana.

Para tal fin se han seleccionado algunas de las fuentes que contienen elementos, definiciones, testimonios e indicios que nos puedan ayudar a establecer cuál fue en derecho romano clásico el contenido y alcance del término solutio. En un segundo momento pasaremos a hacer lo propio con el término satisfactio, el cual juega un papel importante en la determinación del significado del primero, pues se trata de un concepto que aparece en las fuentes jugando un rol aparentemente contradictorio con relación a la solutio: en ocasiones aparece como sinónimo y en otros casos como su antítesis. Se trata, entonces, de esclarecer cuáles sean los límites y las diferencias entre los dos conceptos, a fin de despejar el verdadero ámbito de la solutio. 


\section{Reflexiones históricas sobre la transformación de la solutio entre los periodos arcaico y clásico del derecho romano}

\section{A. En derecho romano arcaico el término solutio se identifica fundamentalmente con la idea de liberación de responsabilidad}

A primera vista puede decirse que la solutio es el concepto que en derecho romano mejor corresponde a la actual noción de cumplimiento. No obstante, en Roma el significado etimológico y jurídico de solvere, más que con "cumplir", se identifica con liberar, desatar, disolver ${ }^{\mathrm{I}}$, ello especialmente en el periodo arcaico.

Lo anterior tiene una explicación histórica que nos remonta al origen de la obligación, el cual se encuentra relacionado con el pago de una suma de dinero a título de pena (poena) para desagraviar a la víctima de un delito, quien renunciaba a la vindicta, como sanción aflictiva, a cambio de una composición económica. Dicho pago constituyó más un rescate que una prestación.

En el ámbito de los actos lícitos surgieron en los orígenes figuras como los vades y los praedes $^{2}$, el nexum y la sponsio. Respecto de las dos primeras figuras, resulta importante resaltar la existencia de una relación física entre el obligado y su acreedor desde el momento en que surgía el compromiso hasta que el deudor mismo o un tercero pagara y extinguiera así dicha situación, en la que la responsabilidad -como elemento integrante de la obligación- se encontraba materializada y prevaleciente en relación con el débito.

Por ello se sostiene ${ }^{3}$ que originariamente la solutio estaba dirigida a obtener la liberación de la responsabilidad, y sólo posteriormente representó la idea de ejecución de la prestación debida, o sea, de cumplimiento. Tal estado de cosas puede notarse claramente en la necesidad de observancia de ritos para la materialización de la solutio arcaica. Tales ritos fueron fundamentalmente la solutio per aes et libram y la acceptilatio.

I Solazzi, S., L'estinzione delle obbligazioni nel diritto romano, 2. ${ }^{\text {a }}$ ed., Napoli, Jovene, I935, 9; Cruz, S., Da "solutio". Terminologia, conceito e características, e análise de vários institutos afins, I, Épocas arcaicas y clasicas, Coimbra, I962, 36. Estos autores, además, ponen de relieve que solvere corresponde al contrario de ligare, concepto este último que describe la naturaleza inicialmente física del vínculo obligatorio.

2 Talamanca, M., Istituzioni di diritto romano, Milano, Giuffrè, I990, 504, señala que las figuras de los vades y los praedes podían también ser utilizadas en el contexto de la composición económica de un delito, al ser usados como rehenes que se dejan en poder del ofendido como garantía del pago de la poena. Marrone, M., Istituzioni di diritto romano, Palumbo, 2006, 404, explica: "En las relaciones entre privados a los praedes se recurría en la legis actio sacramenti in rem para garantizar que la parte a la cual el pretor había asignado la posesión provisional de la cosa en controversia, la restituyera al adversario en caso de sucumbir [...] A los vades se acudía también en las legis actiones, para garantizar la comparecencia en juicio de la parte convenida cuando la audiencia era aplazada para otra fecha" (todas las traducciones del italiano son propias). 
La solutio per aes et libram 4 constituía un rito que solemnizaba el acto de pagar una suma de dinero, a través del peso de un trozo de bronce -es de aclarar que en los inicios tal suma de dinero no consiste en un conjunto de moneda acuñada susceptible de ser contada, por lo que resultaba necesario pesar con una balanza (libram) el bronce en el que consistía el dinero- que el deudor entregaba a cambio de poner fin, como ya se ha dicho, a una situación actual de responsabilidad, o evitar la consolidación de los efectos propios de la manus iniectio5.

Dentro de este contexto, los elementos que integran el acto per aes et libram no pueden considerarse como una mera formalidad, sino que son por sí mismos la materialización de la solutio, la cual, por lo tanto, consistió en la conjugación de la forma y la prestación, puesto que la correcta ejecución de la prestación exigía que se pesara el metal, a fin de contabilizarlo, pues de lo contrario no podría conocerse la exactitud de la suma entregada. Por ello, reiteramos, con el mismo acto se ejecutaba la prestación y se celebraba una solemnidad.

Lo mismo ocurría con la acceptilatio, aunque la identidad entre rito y solemnidad era menos patente. Aquí, la importancia de la solemnidad se evidenciaba en que la acceptilatio era el mecanismo utilizado para formalizar el cumplimiento de las obligaciones nacidas por medio del pronunciamiento de unas palabras rituales (certa verba), de manera que su extinción requería, igualmente, la pronunciación de unas palabras solemnes que efectivizaran el poder liberatorio que la prestación por sí misma no tenía. De esta manera, la declaración solemne se revelaba fundamentalmente como la confesión de haber recibido. Así, tras la pronunciación de las palabras propias del rito se procedía con la ejecución del débito, el cual ya no podía ser desconocido por el acreedor.

En conclusión, durante esta época, estos actos materializaban el cumplimiento y lo dotaban de eficacia liberatoria, de ahí la imperiosa necesidad práctica de su observancia ${ }^{6}$, puesto que en la época arcaica el cumplimiento por sí mismo no producía, ipso iure, la extinción de la obligación.

4 Utilizada, durante este periodo, para liberar al nexus y, más adelante, al addictus. En el primer caso, el nexus, deudor de una suma de dinero, pone a disposición del acreedor su persona física, con el objeto de garantizarle la devolución del préstamo. En el caso del addictus estamos delante de una persona sujeta al proceso ejecutivo de la legis actionis per manus iniectionem, el cual tiene como presupuesto la existencia de una sentencia previa en la que se ha establecido que el deudor cometió un incumplimiento de sus obligaciones. La condena así emanada, era siempre estimada en dinero mediante el procedimiento de la litis aestimatio, por el que las partes, valiéndose de un juramento, terminaban por señalar un valor económico a su contienda. Cfr. Talamanca, Istituzioni, cit., 356; Marrone, Istituzioni, cit., 403.

5 Solazzi, L'estinzione, cit., I5, I9; Cruz, Da "solutio", cit., 36 ss. Este último autor resalta que durante el periodo arcaico solvere-solutio son conceptos íntimamente ligados con pecunia. Solvere era desatar al obligado tras la correspondiente entrega de pecunia al acreedor; luego, con el surgimiento de la moneda acuñada, viene a identificarse con la entrega misma del dinero. Por lo anterior, concluye que la solutio arcaica no era cumplimiento, era el pago real y solemne de una suma de dinero destinada al rescate de sí mismo o de otro de un cautiverio.

6 Solazzi, L'estinzione, cit., I 8, I9. 
Sin embargo, ya antes de la edad clásica7 esta situación empezó a sufrir una transformación que dio lugar a reconocer plena eficacia liberatoria al pago de una suma de dinero sin la observancia de las formalidades correspondientes, y en general para la misma época la solutio, desprovista de forma, como expresión misma del cumplimiento, logra un efecto extintivo ipso iure de cualquier obligación. En doctrina se han sostenido varias propuestas para explicar cómo adquirió autonomía extintiva la solutio, y cómo esta asumió el sentido de ejecución de la prestación debida, y se alejó del inicial significado de mera liberación de una responsabilidad.

Así, Siro Solazzi ${ }^{8}$ sostiene que esta transformación en los efectos reconocidos a la solutio está ligada, en el caso de la solutio per aes et libram, a la aparición de la moneda acuñada, puesto que con ello se tornó meramente simbólico el acto de pesar el trozo de bronce. Por esta vía, el cumplimiento dejó de ser parte integrante del rito y la solutio per aes et libram se transformó en la suma de dos actos, el cumplimiento y el ritual de solemnización, para llegar a ser finalmente un mero acto simbólico.

Igual suerte habría de correr la acceptilatio, la cual desde su surgimiento estaba integrada por dos actos: la ejecución de la prestación y el acto solemne de recibirlo. De esta manera, tanto la solutio per aes et libram como la acceptilatio terminaron por convertirse en solemnidades que se usaron como ficciones para perfeccionar la remisión del débito (cumplimiento ficto) ${ }^{9}$, de ahí que fueran llamadas por Gayo "imaginariae solutio" ${ }^{\circ}$.

Por esta vía, el autor adhiere a la tesis según la cual, reconocida eficacia extintiva a la forma, independientemente de la prestación, se debió llegar al reconocimiento de eficacia extintiva también a la prestación, con independencia de la forma.

A estas razones puede sumarse la explicación que presenta Sebastião Cruz ${ }^{\mathrm{II}}$, quien sostiene que la solutio debe analizarse en estricta relación con las etapas de evolución de la obligación, puesto que los cambios en la estructura y función de

7 Solazzi, L'estinzione, cit., 22; sostiene el autor que la transformación de la solutio solemne en modo de remisión del débito es indicativa del momento más antiguo y seguro en que el pago informal adquiere plena eficacia extintiva, es decir, antes de la edad clásica.

8 Solazzi, L'estinzione, cit., I 7 ss.

9 Marrone, Istituzioni, cit., 520.

ı Instituciones Jurídicas de Gayo, texto y trad. Francisco Samper, Santiago de Chile, Jurídica de Chile, 2000, 287 "Gai. 3,I69. Asimismo, se extingue una obligación mediante aceptilación, que es como una forma de pago abstracta. Si quisieras perdonarme lo que te debo por una obligación contraída mediante palabras, podrá hacerse permitiendo tú que yo diga: ‘¿Das por recibido lo que te prometí?', y tú respondes 'Doy por recibido"'.

"Gai. 3, I 73. Y hay otra clase de pago abstracto, que se realiza por el bronce y la balanza, y se admite en ciertos casos, como si la deuda procede de algo que se gestionó por el bronce y la balanza, o de una sentencia judicial".

I I Cruz, Da "solutio", cit., I 3 . 
esta última determinaron, igualmente, una variación en la estructura y función de la solutio.

Por lo tanto, la naturaleza solemne de la solutio en la época arcaica puede explicarse con referencia a la estructura y función que tenía la obligación en dicho periodo ${ }^{\mathrm{I} 2}$, en el que sobresalía la responsabilidad sobre el débito, y en donde la primera era fundamentalmente personal e implicaba un ligamen físico del deudor, y el débito era esencialmente dinerario. En consecuencia, la solutio arcaica no era cumplimiento, sino pago real y solemne de una suma de dinero, destinada a la liberación de sí mismo o de otro de una situación actual de responsabilidad ${ }^{\mathrm{I}}$.

Así, la adquisición de plena eficacia extintiva del cumplimiento se explica, igualmente, por medio de la transformación que sufrieron la estructura y la función de la obligación en la época clásica ${ }^{\mathrm{I}}$. Para este periodo se consideraba que la obligación otorgaba el derecho a exigir una prestación, razón por la cual solvere fue, en consecuencia, un acto de cumplimiento que extinguía la obligación por sí mismo, puesto que permitía la realización de la finalidad intrínseca de la obligación, la cual, en esta época, se identificaba con la ejecución de un comportamiento en favor del acreedor. Por esto, en la época clásica se pagaba para cumplir y satisfacer al acreedor, y no sólo para liberar al deudor de una responsabilidad, llamémosla preventiva, como antaño sucedía. Aunque, en todo caso, el deudor sí se liberaba, pero ya no de un vínculo material, sino ahora de uno jurídico.

El recorrido histórico que hemos hecho hasta este punto nos sirve de contexto introductorio para facilitar la comprensión del análisis de las fuentes de derecho romano con el que vamos a proseguir, el cual resulta indispensable para abordar la dimensión jurídica del problema que nos proponemos estudiar.

\section{B. El formulario de la solutio per aes et libram reporta el más antiguo significado de solutio como liberatio, tal y como lo testimonia Gai. 3, I 74}

La primera fuente que hemos de estudiar es, sin duda, el formulario de la solutio per aes et libram, recordado por Gayo en sus Instituciones. El texto dice lo siguiente: 
GAI. 3, I74: Se hace de la siguiente manera: Se toman no menos de cinco testigos y un libripens. Luego la persona a quien se le cancela la obligación debe decir: "Con este bronce y esta balanza, te pago y me libero de tantos miles de sestercios que te debía o a los había sido condenado. Aquí peso, conforme a la ley pública, la primera y la última libra que te debía". Seguidamente, golpea la balanza con la moneda y se la da a la persona que le cancela la deuda, a modo de pago $^{15}$.
Adbibentur autem non minus quam quinque testes et libripens. Deinde is, qui liberatur, ita oportet loquatur: quod ego tibi tot milibus condemnatus sum, me eo nomine a te solvo liberoque boc aere aeneaque libra hanc tibi libram primam postremamque expendo "secundum" legem publicam ${ }^{\mathrm{I}}$.

En esta parte de su obra, Gayo analiza las imaginariae solutionis que eran, para la época, la solutio per aes et libram y la acceptilatio. Desde el \$ I 73 el jurista comienza a ocuparse de la primera, la cual ya era una mera formalidad incorporada en un acto abstracto, idóneo, por ejemplo, para perfeccionar una remisión del débito. Sin embargo, no analizaremos el pasaje desde la perspectiva que enfatiza la utilización que se dio a estas figuras una vez perdida su connotación sustancial originaria.

Interesa este fragmento, sobre todo, para evidenciar el carácter solemne y sustancial de la solutio per aes et libram en la época arcaica, periodo en el cual tenía muy diversas implicaciones, pues el cumplimiento y la solemnidad eran una y la misma cosa.

En primer lugar, es necesario señalar que Gayo nos está reportando el formulario de la solutio per aes et libram ex iudicati causa ${ }^{17}$, con lo que testimonia un alargamiento de la utilización de la solutio con balanza en su contexto originario, es decir, la liberación del nexus, aplicada ahora en el contexto de la manus iniectio.

I 5 Instituciones Furídicas de Gayo, cit., 289.

I6 El texto completo del fragmento es el siguiente: Gai. 3, I74: Adbibentur autem non minus quam quinque testes et libripens. deinde is, qui liberatur, ita oportet loquatur: quod ego tibi tot milibus condemnatus sum, me eo nomine a te solvo liberoque boc aere aeneaque libra banc tibi libram primam postremamque expendo "secundum" legem publicam. Deinde asse percutit libram eumque dat et a quo liberatur, veluti solvendi causa.

I CARDILli, R., "Lege XII tabularum praeposita iungitur interpretatio", en Estudios de derecho civil, Obligaciones y contratos, Libro homenaje a Fernando Hinestrosa - 40 años de Rectoría I963-2003, 220, quien en el análisis de la expresión “'secundum' legem publica” enfatiza que "es necesario acentuar el hecho de que Gayo no está reportando el formulario de la nexi liberatio, sino la solutio per aes et libram ex iudicati causa. Tal precisión nos reenvía a la manus iniectio iudicati que es reconducida por la tradición a las XII Tablas y que materializaría la primera forma de manus iniectio fundada en una lex publica, acto solemne ya ritualizado de otra manera antes de las XII Tablas". El mismo fragmento es analizado igualmente en referencia con la expresión " 'secundum' legem publicam" por Biondi, B., "Lex e ius", Revue internationale des droits de l'antiquité, $3 .{ }^{a}$ serie, t. XII, I965, I90. 
Dentro de este contexto el jurista nos deja ver una estratificación evolutiva en su contenido ${ }^{18}$.

Así las cosas, el estrato más antiguo puede identificarse en las palabras " $a$ te solvo liberoque boc aere aeneaque libra" (te pago y me libero) que identifican los efectos liberatorios típicos del formulario original ${ }^{19}$, en el cual puede notarse nítidamente la relación íntima del término solutio con su objetivo fundamental: la liberatio (solvo liberoque). Ya que en esta época lo que se pretende, principalmente, es liberar al deudor de su responsabilidad, más que cumplir un acto en favor de los intereses del acreedor.

Un estrato más reciente se identifica, como ya se ha dicho, en la utilización extensiva de la solemnidad de la solutio con balanza, para liberar al iudicatus sometido a la manus iniectio ${ }^{20}$; en donde, no obstante, aún conserva su significado remoto de liberación, pero, en este caso, obtenida por aquel ejecutado en el proceso de la manus iniectio prevista por las legis actiones.

Finalmente, llegamos al estrato final de esta evolución, que se identifica con la descripción que hace Gayo de esta solemnidad como imaginariae. Acá, es claro que hemos llegado a una etapa de evolución de la figura en la cual ha adquirido plena solidez la identificación de solutio con un concepto de cumplimiento, sustancial, y, en consecuencia, el ritual per aes et libram terminó por usarse sólo como ficción de cumplimiento para solemnizar la remisión del débito. Resulta claro que el contenido material de la solutio se ha desprendido totalmente de su forma, aunque no de su significación de acto de liberación, significación que -como hemos de verlo- habrá de pervivir incluso hasta nuestros días, en donde aún se considera que el deudor cumplidor es un deudor liberado.

i 8 En un sentido diferente, St. Tomulesco, C., "Quelques petites études de droit romain", Bullettino dell'Istituto di diritto romano 'Vittorio Scialoja', vol. LxxxII, I979, I05, quien sostiene la presencia de un anacronismo en el texto, además de afirmar que es errónea la información que contiene, entre otros motivos porque "es inverosímil que a mediados del segundo siglo de nuestra era los Romanos continuaran pagando sus deudas pesando libras de cobre".

i9 Cfr. Cardilli, "Lege XII tabularum praeposita iungitur interpretatio", cit., 22 I; MAGdelain, A., "L'acte per aes et libram et l'auctoritas", Revue Internationale des droits de l'antiquité, t. xxvIII, I98 I, I33; De Martino, F., "Riforme del iv secolo a.C.", Bullettino dell'Istituto di diritto romano 'Vittorio Scialoja', vol. LxxviII, I 975, 42.

20 Gai. 3, I73: ... si quid ex iudicati causa debeatur; CARDILLI, "Lege XII tabularum praeposita iungitur interpretatio", cit., 230, quien sostiene que dicha extensión interpretativa fue operada por los pontífices: "Estos consideraron que se debía extender la utilización del acto libral de disolución del estado de responsabilidad derivada del nexum a la hipótesis de ejecución personal sobre el deudor juzgado prevista por la ley de las xir Tablas". En el mismo sentido explica Magdelain, "L'acte per aes et libram et l'auctoritas", cit., I 27 : "Los pontífices ejercen su imaginación para extraer un acto nuevo de una institución más antigua [...] El acto con el bronce y la balanza permitirá tanto la venta de un bien por medio de la mancipación como, en el nexum, obtener un préstamo de dinero. Bajo la forma de solutio habría de encontrarse bien un pago, bien la remisión de una deuda”. 


\section{La noción de cumplimiento perfilada por los juristas del periodo clásico: la pervivencia de una tradición reflejada en la duplicidad de significados que conviven al interior del término solvere}

En las fuentes del derecho romano conviven testimonios que reflejan la existencia de dos acepciones asociadas al término solutio. Por una parte, pueden encontrarse textos que testimonian que este se usaba para indicar en general la extinción de las obligaciones, y por otra parte encontramos textos en los que solutio, o alguna de las formas verbales de solvere, permitía identificar de manera restringida la descripción del cumplimiento de la prestación debida.

Lo anterior encuentra una explicación en el desarrollo histórico de la figura $^{21}$, la cual pasó de representar la liberación material del deudor (liberatio) de una responsabilidad en cabeza suya, a significar la disolución de un vínculo jurídico, ya no por virtud del pago dirigido fundamentalmente a extinguir una situación actual de responsabilidad, sino por la ejecución de la prestación debida ${ }^{22}$.

Así, la evolución y transformación de la estructura de la obligatio determinó también un cambio en el término solutio por medio de una especificación de su significado en la idea de cumplimiento, no obstante lo cual su utilización en sentido lato, o como concepto general que representa la extinción de las obligaciones $^{23}$, no desapareció.

Pasemos entonces al análisis de algunas fuentes del derecho romano que testimonian la coexistencia de estos dos usos del término solutio.

\section{A. La regla "del mismo modo en que se contrata, ha de cumplirse" y el término solutio en Quinto Mucio Escévola. Exégesis de D. 46,3,80 a la luz de las dos acepciones de solvere}

Ahora, hemos de hacer mención a D. 46,3,80, que corresponde a un texto de Pomponio en su obra ad Quintum Mucium, y que nos trae testimonios acerca del

2 I Cfr. supra A.I.

22 Solazzi, L'estinzione, cit., I 2-I4, quien pone de presente que los dos significados que han sido asignados a solvere se han asociado con los dos elementos de los que se compone la obligación (débito y responsabilidad) y con el distinto grado de importancia que estos tuvieron en las épocas arcaica y clásica del derecho romano. Pues en la primera tuvo preponderancia la responsabilidad y desde la segunda el rol central lo asume el débito. En el mismo sentido cfr. Cruz, Da "solutio", cit., I3; Melillo, G., In solutum dare. Contenuto e dottrine negoziali nell'adempimento inesatto, Napoli, Jovene, I970, 27.

23 Solazzi, L'estinzione, cit., I I: "Il pretore usava ancora la locuzione solvere col suo significato antico. Certamente il pretore ba desunto l'espressione dal formulario della manus iniectio, in cui era detto (Gai. IV. 2I) quandoc non solvisti, e ha nel proceso formulare trasportato del procedimento delle legis actiones, insieme con le parole, anche il loro antico significato". 
contenido y alcance del término solutio ya desde los tiempos de la República, y que por lo tanto asume una trascendental importancia para nosotros.

Pomponio; Comentarios a Quinto Mucio, libro iv.- De la manera que se contrató alguna cosa debe ser cumplido el contrato, de suerte que, cuando se haya contratado mediante una cosa, se debe pagar con la cosa, ó, cuando hayamos dado en mutuo, se debe devolver otra cantidad. Y cuando contratamos verbalmente alguna cosa, la obligación se debe disolver ó con la cosa, ó verbalmente; verbalmente, como cuando al prometedor se le da por pagado, con la cosa, como cuando entrega lo que prometió. Igualmente, cuando se contrató compra, ó venta, ó locación, como quiera que se pueden contratar por el nudo consentimiento, se pueden disolver también por el disentimiento contrario ${ }^{24}$.
Pomponius libro quarto. ad Quintum Mucium.- Prout quidque contractum est, ita et solvi debet: ut, quum re contraxerimus, re solvi debet: veluti quum mutum dedimus, ut retro pecuniae tantundem solvi debeat. Et quum verbis alquid contraximus, vel re vel verbis obligatio solvi debeat; verbis, veluti quum acceptum promissori fit, re, veluti quum solvit, quod promisit. Aequae quum emtio, vel venditio, vel locatio contracta est, quoniam consensu nudo contrabi potest, etiam dissensu contrario dissolvi potest.

Aunque tradicionalmente la doctrina ha estudiado este fragmento en el contexto de la determinación de la noción de contrato en derecho romano, nosotros adoptaremos una lectura diferente del texto, recientemente propuesta ${ }^{25}$, conforme a la cual el interés definitorio de Quinto Mucio estaba realmente enderezado hacia el solvere obligationem más que hacia el contrabere. Desde tal perspectiva encontraríamos una evidencia de gran importancia en la pesquisa sobre la tradición que precede al término solutio.

Para analizar este fragmento es necesario, en primer lugar, definir el contexto temático al que pertenece. En la obra de Pomponio, el texto corresponde al libro iv De legati y más específicamente al tema de liberatione legata, es decir, al legado con el cual se dispone la remisión de un débito en favor del legatario. En cuanto al contexto en el que el propio Quinto Mucio escribía ${ }^{26}$, se cree no sólo

24 García del Corral, I., Cuerpo del derecho civil romano, t. III, Barcelona, Lex Nova, i889, 6 I 3.

25 Fiori, R., "Contrahere e solvere obligationem in Q. Mucio Scevola”, en Fides Humanitas Ius, Studi in onore di Luigi Labruna, III, Napoli, Editoriale Scientifica, 2007, a quien seguimos muy de cerca no sólo en su planteamiento sino también como guía sobre el estado del análisis de este fragmento en la doctrina.

26 Recordemos que el fragmento en análisis pertenece a una obra caracterizada por contener comentarios de un jurista, en este caso Pomponio, a una obra de otro jurista, en este caso Quinto Mucio. De esta manera el jurista comentador transcribía un lema de la obra del jurista comentado y a continuación hacía sus observaciones. El fragmento objeto de estudio era introducido por frases como Quintus Mucius ait/scribit o tal vez sólo Quintus Mucius, pero en el Digesto fueron recortadas todas estas referencias, por lo que resulta difícil saber cuál es el lema y cuál es el comentario. 
que entre ambos juristas existía una identidad temática, es decir, que también Quinto Mucio estaba tocando el tema de liberatione legata ${ }^{27}$, sino además que la totalidad del texto puede atribuirse a este último jurista ${ }^{28}$. En este orden de ideas, es factible suponer que el jurista se proponía distinguir las diversas formas de remisión por legado en correspondencia con las diversas formas de contraer las obligaciones (obligationes contractae) ${ }^{29}$.

Para la comprensión del texto ha resultado difícil explicar la relación que existiría entre la primera frase del mismo ("de la manera que se contrató alguna cosa debe ser cumplido el contrato": Prout quidque contractum est, ita et solvi debet), que definiría una regla conforme a la cual las obligaciones deben extinguirse de la misma manera en que fueron constituidas, y el hecho de que respecto a las obligationes verbis contractae -aquellas obligaciones que requerían de la pronunciación de las palabras solemnes para sus surgimiento- se sostenga que en estas el deudor puede liberarse bien por medio de la entrega de una cosa, bien a través del pronunciamiento de unas palabras solemnes (vel re vel verbi... solvi debeat). Lo cual introduciría una contradicción frente a la regla inicialmente enunciada.

Sin embargo, la contradicción se desvanece cuando se admite que la remisión es el centro fundamental de la definición de Quinto Mucio. Visto así el fragmento, puede concluirse que el jurista encontró como primera dificultad la amplitud semántica de la palabra solutio, la cual en su sentido lato podía abarcar a la remisión como uno de los mecanismos de extinción de las obligaciones. Razón por la cual decidió articular y armonizar su discurso valiéndose de los dos niveles de significado que tiene la expresión solutio. Por lo que frente a cada una de las categorías de obligationes hace referencia a la remisión como una posibilidad de extinción, que lógicamente no descarta el cumplimiento. Así, de las obligaciones re habla de su cumplimiento ("cuando se haya contratado mediante una cosa, se debe pagar con la cosa, ó, cuando hayamos dado en mutuo, se debe devolver

27 FIORI, “Contrahere e solvere obligationem in Q. Mucio Scevola”, cit., I969, I97 I, pone de presente la discusión doctrinal en torno a la determinación del tema del que hablaba Quinto Mucio. En ese sentido resulta importante mencionar que también se ha sostenido que el jurista hacía referencia al tema como una reflexión autónoma que habría sido inducida por una referencia lexical al verbo solvere. Sin embargo, Fiori defiende la postura conforme a la cual Quinto Mucio también analizaba el asunto de la remisión legada con base en un análisis de los escolios de los Basiliscos en cuya "reproducción del pasaje están presentes una referencia a la solutio respecto de las obligationes re contractae, y dos llamados a formas de remisión de las obligationes verbis y consensu contractae". Por lo que se llega a la conclusión de que la utilización de la palabra solutio se hizo como un llamado a la remisión en cuanto mecanismo de extinción de las obligaciones re. Pues de entenderse la referencia a solutio con sentido de cumplimiento, se llegaría a la absurda conclusión de pensar que los Basiliscos consideraban que sólo las obligaciones re podían extinguirse por cumplimiento.

28 Fioni, "Contrabere e solvere obligationem in Q. Mucio Scevola", cit., I960, I96I, pone de presente que se ha discutido acerca de una posible intervención de Pomponio en el contenido del fragmento.

29 Ibíd., nota 46. 
otra cantidad": quum re contraxerimus, re solvi debet: veluti quum mutum dedimus, ut retro pecuniae tantundem solvi debeat) sin descartar la posibilidad de que el texto original haya traído una referencia a la remisión ${ }^{\circ}{ }^{\circ}$, que es lo que nos indica el análisis de los Basiliscos ${ }^{3}$, y la ubicación palingenésica del fragmento.

Por su parte, respecto de las obligaciones verbis habla tanto de su cumplimiento como de su remisión ("verbalmente, como cuando al promitente se le da por pagado; con la cosa, como cuando entrega lo que prometió": verbis, veluti quum acceptum promissori fit, re, veluti quum solvit). Y finalmente, respecto de la obligationes consensus contractae nuevamente encontramos una referencia explícita a su remisión por medio del disentimiento contrario (dissensu contrario) y una referencia implícita al cumplimiento, que se puede deducir del potest al final del texto, el cual nos indica que la obligación en este caso puede ser extinguida sea con el cumplimiento, sea con el dissensus ${ }^{32}$.

En este orden de ideas el texto nos revela, más que una supuesta regla de la simetría en la constitución y la extinción de las obligaciones, la existencia de una ambivalencia semántica en el término solvere que se remonta a una antigua tradición dentro del contexto jurídico romano, y que nos ayuda a comprender los acercamientos de juristas posteriores a este concepto como manifestaciones de la continuidad de dicha tradición.

\section{B. Gai. 3, 68 contiene un concepto sustancial de cumplimiento, pero también refleja que con solutio se podía significar, en general, la liberación del deudor como manifestación perviviente de su connotación arcaica}

Gayo, 3,I68. Acábase principalmente la obligación por el pago de lo que se debe; pero ¿en rigor quedará libre el deudor cuando consintiendo el acreedor, le pagare una cosa por otra? Nuestros maestros piensan que sí; mas los autores de la escuela contraria sostienen que subsiste la obligación, si bien podrá el deudor oponer la excepción de dolo malo a una nueva petición del acreedor ${ }^{33}$.
GAI. 3,I68. Tollitur autem obligatio praecipue solutione eius, quod debeator. Vnde quaeritur, si quis consentiente creditore aliud pro alio solverit, utrum ipso iure liberetur, quod nostris praeceptoribus placet, an ipso iure maneat obligatus, set adversus petentem exceptione doli mali defendi debeat, quod diversae scholae auctoribus uisum est. debido, o en palabras de Gayo, como una imaginariae solutio. 
El texto empieza por señalar que la obligación se termina, se extingue, principalmente por la solutio de aquello que se debe. Y continúa planteando un interrogante acerca de la posibilidad de producir el mismo efecto (ipso iure liberetur) con el ofrecimiento al acreedor de una cosa diversa a la originalmente debida (aliud pro alio solverit), ello, claro, bajo la condición de existencia de consentimiento por parte del acreedor (si quis consentiente creditore).

En general, la doctrina ha identificado el texto como una de las principales fuentes de las que se puede concluir que solutio corresponde a nuestra actual idea de cumplimiento 34 -de ahí su importancia definitoria para la materia-, y, por lo tanto, se ha considerado que acá el concepto es usado en su sentido restringido.

Según la perspectiva diversa de Melillo35, el texto, al especificar con las palabras praecipue solutione eius quod debetur ("principalmente cumpliendo con aquello que debemos"), deja una amplitud considerablemente grande al término solvere; sostiene entonces que también en la parte inicial del fragmento el jurista ha usado la palabra en su sentido amplio. Pues, en efecto, tanto la expresión eius quod debetur como praecipue son indicadoras de un uso de solvere capaz de abarcar otras causas de extinción de las obligaciones y no sólo el cumplimiento ${ }^{36}$.

Nosotros consideramos que en la primera parte del texto (tollitur - quod debeatur) Gayo está usando una acepción restringida del término solvere, es decir, en el plano del cumplimiento, el cual resalta como principal (praecipue). Lo que tiene todo el sentido siendo que el cumplimiento es el objetivo natural de la relación obligatoria; ella está dirigida, desde su nacimiento, a cumplirse, es el motivo principal de su existencia. Es en ese sentido que consideramos que es usada la expresión, y no tanto para indicar que es una de las vías de extinción sin excluir las demás, sino para enfatizar que es la vía principalísima, vista la estructura funcional de una obligación.

En la segunda parte del texto, dedicada a los efectos liberatorios de la datio in solutum ${ }^{37}$, Gayo usa el término solutio (aliud pro alio solverit) con un sentido amplio, es decir, en su otro nivel semántico, como descriptiva de otros mecanismos de extinción de las obligaciones. Bajo esa premisa, consideramos manifiesta la existencia de una ambivalencia en el significado de la palabra, que viene usada

34 Cfr., p. ej., Solazzi, L'estinzione, cit., io; Di Marzo, Istituzioni, cit., 208; Branca, G., "Adempimento. Diritto romano e intermedio", Ed. ı, Milano, Giuffrè, I 958, 549.

35 G. Melillo, In solutum dare, Contenuto e dottrine negoziali nell'adempimento inesatto, Napoli, Jovene, I970, 24: "el eius quod debeatur no tendría ningún sentido si el jurista no tuviera contemporáneamente presente la hipótesis de una prestación diversa de aquella debida, también constitutiva de solutio".

36 Melillo, In solutum dare, cit., 24, resalta que en Gayo también pueden encontrarse manifestaciones de un uso restringido de solutio, como en D. I3,7, Io en el que el jurista niega al deudor el ejercicio de la actio pigneratia cuando pretendiera sustituir, sin el consentimiento del acreedor, la prestación originaria por un aliud.

37 Sobre la datio in solutum cfr., por todos, SAccoccio, A., Aliud pro alio consentiente creditore in solutum dare, Milano, Giuffrè, 2008. 
tanto para enfatizar el lugar prioritario del cumplimiento, vista la función de la obligación, como para designar una dación en pago, respecto de la cual se indaga, precisamente, su capacidad liberatoria en comparación con el cumplimiento, sin dejar por ello de usar el mismo concepto para designar los dos fenómenos.

\section{Textos de Ulpiano y Paulo testimonian que durante todo el periodo clásico existe una duplicidad de significados que conviven en el término solvere}

La misma tradición en el uso del vocablo solutio la podemos encontrar en D. 50, I6, I 76 que contiene una opinión de Ulpiano en los siguientes términos:

Ulpiano; Comentarios a Sabino, libro xxuv. Está determinado que con la palabra "pago" [solutio] se ha de entender también toda satisfacción; decimos que "paga" el que hizo lo que prometió hacer ${ }^{38}$.
ULPIANUS libro quadragensimo quinto ad Sabinum. 'Solutionis' verbo satisfactionem quoque omnem accipiendam placet 'solvere' dicimus eum qui fecit quod facere promisit.

El comentario de Ulpiano pertenece, dentro de su obra, a un libro dedicado al estudio de verborum obligatione. Nos dice en la primera parte que el término solutio abarca toda satisfactio (solutionis - accipiendam placet), y en la segunda parte, que quien ha hecho lo que prometió hacer, ha llevado a cabo un solvere.

En cuanto a esto último, podemos notar que Ulpiano hace una descripción de solutio en términos bien restringidos a la idea de cumplimiento, puesto que sostiene que ha observado una conducta reconducible al verbo solvere aquel que ha observado el compromiso que tenía, aquel que ha actuado conforme a lo que ha dicho al obligarse. Se resalta entonces la correspondencia entre el compromiso que ha dado origen a la obligación y aquello que posteriormente se ha hecho. Así, podemos ver que si bien el texto pertenece a un contexto específico (de verborum obligatione), ello no implica que la descripción acá hecha de solvere sea únicamente predicable de este tipo de obligaciones, sino al contrario, que se trata de la aplicación de un concepto general a un asunto específico.

En lo que hace a la primera parte del texto, es claro que revela la utilización de solutio en su sentido amplio, capaz de abarcar también otras modalidades de contentamiento del acreedor, y no sólo el cumplimiento como el medio más idóneo de satisfacción de los intereses del acreedor. Lo cual, a su vez, permite notar que para la época de Ulpiano ha adquirido solidez una significación sustancial de solutio que acentúa su relación con el estado de sosiego del acreedor, descrito con la expresión satisfactio, utilizada en su sentido amplio.

Todo lo cual demostraría, una vez más, la convivencia de una duplicidad de significados en el término solvere, como parte de una tradición que, en esta oportu- 
nidad, nos reenvía al propio Sabino y que permanece en juristas como Ulpiano ${ }^{39}$, y aún más explícitamente en Paulo, quien en D. $46,3,54^{[40]}$ habla de la solutio en los siguientes términos:

Paulo; Comentarios al edicto, libro Lvi. La palabra pago corresponde a toda liberación hecha de cualquier modo, y se refiere más bien a la substancia de la obligación, que al pago del dinero ${ }^{4 \mathrm{I}}$.
PAULUS libro quinquagensimo sexto ad edictum. Solutionis verbum pertinet ad omnen liberationem quoquo modo factam magisque ad substantiam obligationis refertur, quam ad nummorum solutionem.

El texto de Paulo, conforme a la lectura que del mismo hace Melillo ${ }^{42}$, es explícito en la exposición de los dos significados que tiene solutio. El jurista sostiene que solutio abarca, en términos generales, cualquier liberación del deudor, y a continuación concreta la afirmación explicando que hay solutio no sólo con el pago de dinero -está refiriéndose, de manera específica, a la prestación típica en materia de actio iudicati, que es justamente la materia sobre la que versa el fragmento en su ubicación palingenésica-, con lo que está haciendo referencia no sólo al cumplimiento ("al pago del dinero": quam ad nummorum solutionem) sino también a cualquier medio de liberación que mire la sustancia misma de la obligación ("se refiere más bien a la substancia de la obligación": liberationem quoquo modo factam magisque ad substantiam obligationis).

Lo que no deja dudas acerca de la existencia consolidada de un concepto sustancial y restringido de solutio que identifica el cumplimiento como aquella conducta que satisface los intereses del acreedor, que por ello mismo corresponde a la finalidad estructural y funcional de la obligación. Significado que convive con aquel amplio y formal que contiene el legado del originario contexto arcaico

39 Tal y como puede notarse en D. 42,I,4,7 Ulpianus libro quinquagensimo octavo ad edictum $\$ 7$ : Solvisse accipere debemus non tantum eum qui solvit, verum omnen omnimo, qui ea obligatione liberatus est, quae ex causa iudicati descentit. Acá, según Melillo, In solutum dare, cit., I 7, puede notarse una "duplicidad de acepciones que resulta evidente en la expresión 'solvisse... non tantum qui solvit", lo que permite concluir que Ulpiano conoce y utiliza dos nociones de solvere, y que se refería a la solutio como "el efecto típico del cumplimiento exacto, afirmando que de una cualquiera prestación satisfactoria del condenado brota una plena liberación". Una visión diferente es sostenida por Solazzi, L'estinzione, cit., I I, quien defiende la tesis según la cual en Ulpiano se encuentra esta noción amplia de solutio debido a que en la época clásica el pretor conservó en el edicto sobre la actio iudicata, no sólo la palabra sino también el antiguo significado de solvere, presente en la legis actio per manus iniectionem, de manera que es lógico que dicha acepción permanezca en esta obra de Ulpiano, estando dedicada precisamente a comentar este edicto, tal y como se deduce de su ubicación palingenésica.

40 Conforme a la palingenesia de Lenel, el texto de este fragmento va unido al contenido de D. 50,I6,47 Paulus libro LVI ad edictum. "Liberationis" verbum eadem vim habet, quam solutionis. Y juntos integrarían lo único que queda del libro Lxvi De iudicatis.

4I García del Corral, Cuerpo del derecho civil romano, t. III, cit., 606.

42 Melillo, In solutum dare, cit., 24. 
en el cual la solutio se identificaba, por medio de un acto solemne, con la ruptura del ligamen material entre las partes de la obligación.

El recorrido que hemos hecho no deja lugar a dudas acerca de que el contenido y alcance del término solutio se decanta de toda una tradición del derecho romano en la utilización de dicho concepto, y como tal fue transmitida de jurista en jurista como noción ambivalente que sirvió para describir, en su sentido lato, la extinción de las obligaciones; y en su sentido restringido, el cumplimiento de la prestación debida.

\section{Contenido y alcance del término satisfactio y su relación con el problema del cumplimiento exacto en derecho romano}

Hemos de comenzar por señalar que nos interesa indagar sobre el término $s a$ tisfactio para establecer cuál es su rol dentro del problema del cumplimiento, puesto que tanto las fuentes del derecho romano como la doctrina romanista nos revelan que existe una relación entre ambos. Entonces, resulta importante, primero, entender en qué consiste la satisfactio, para luego hacer un análisis conclusivo acerca de su relación con el cumplimiento.

En lo que hace a la determinación del contenido y alcance del término $s a$ tisfactio es necesario, en primer lugar, poner de presente 43 que existen muchos textos 44 con los que, en su conjunto, se demuestra que bien en la época clásica o bien en la posterior, satisfactio sirvió para identificar, en sentido amplio, cualquier acto de contentamiento del acreedor y, en un sentido restringido, el cumplimiento de la obligación. Pero, adicionalmente, pueden encontrarse casos en los que solutio/satisfactio aparecen no sólo como distintas sino incluso en antítesis.

Tales casos son aquellos en los que a la satisfactio se le reconoce la producción de unos determinados efectos que también podrían producirse con la solutio. Esta circunstancia se presenta cuando con relación a la solutio se producen consecuencias jurídicas que se consideran como dogmáticamente diversas y cuya naturaleza nada tiene que ver con el cumplimiento 45.

Lo anterior ha determinado la existencia de variadas posturas a nivel doctrinario para explicar en qué consistió, en sentido restringido, el término satisfactio.

43 Brasiello, "Satisfactio", cit.

44 Brasiello, "Satisfactio", cit., 5-7. Sin embargo, el autor se limita a pocos textos: Gai. 3,I93; 4, I I 4; 4,74. Se habla de satisfacere creditoribus en Gai. 2, I 55; Scaev. D. I 2,6,67 \$ 2; D. 33,6,7; Ulp. D. 42,6, I, § I; Paul. D. 43,24,6; Pap. D. 39,5,28; Iul. D. 24,3,3 I; Triph D. 49, I 5, I 2 \ I 2 ; C. 4,32, I 5 (234); 4,32, IO (293); 8,40, I I (229); 4,6,2 (22 7); 2,3,7 (2 I 3), entre otros.

45 Brasiello, "Satisfactio", cit., 5. Así, por ejemplo, cuando por virtud de un testamento se establece que la liberación de un esclavo tendrá lugar sólo cuando se hayan pagado las deudas del difunto. O cuando, por efecto natural del cumplimiento del contrato de compraventa, se alcanza una determinada situación jurídica como la transferencia del dominio de la cosa vendida. Finalmente, cuando se está delante de actos lógicamente conexos al cumplimiento, como la cesación del proceso ejecutivo o la paralización de la acción de repetición del pignus. 
En ese sentido se le ha enmarcado dentro del limitado espacio de la satisdatio ${ }^{46}$; se ha sostenido que abarca, en general, el otorgamiento de garantías 47 ; y, en fin, se ha afirmado que la satisfactio abarca todo mecanismo de satisfacción del acreedor diferente del cumplimiento de las obligaciones de dare certum ${ }^{4}$.

Así las cosas, resulta claro que el intento de despejar el panorama para aislar un concepto de contornos definidos y concretos no es fácil.

\section{A. La noción de satisfactio en sentido lato indica la conducta del deudor dirigida a llenar, en diverso grado, las expectativas del acreedor}

Nosotros comenzaremos por hacer mención a algunos fragmentos en los que se hace alusión a satisfactio de una manera que permite detectar una suerte de concepto general. Así, hemos escogido referir el contenido de D. 2,8, I:

Gayo; Comentarios al Edicto provincial, libro v. Del mismo modo se dice satisdación que satisfacción. Porque así como decimos que satisfacemos a aquel cuyo deseo cumplimos, de la misma suerte decimos que satisdamos a nuestro adversario, que de tal modo recibió caución por aquello que de nosotros pidió, que en esta reclamación le aseguramos con los fiadores dados 49 .

Y el contenido de D. 45, I, $\$ 3$ :

Pomponio: libro xxvi ad Sabinum [...] \$ 3 . Mas se dijo recibir satisdación del mismo modo que satisfacer; porque como se le daba a uno aquello con que estaba contento, se dijo que se le satisfacía... ${ }^{\circ}$.
GaIUs libro quinto ad edictum provinciale. Satisdatio eodem modo appellata est quo satisfactio. nam ut satisfacere dicimur ei, cuius desiderium implemus, ita satisdare dicimur adversario nostro, qui pro eo, quod a nobis petiit, ita cavit, ut cum boc nomine securum faciamus datis 'fideiussoribus'.
Pomponius libro xxVI. ad Sabinum [...] $\$ 3$ Satis autem accipere dictum est eodem modo, quo satis facere: nam quia id, quo quis contentus erat, ei praestabatur, satisfieri dictum est...

46 Brasiello, U., "Satisfactio (preliminari e diritto classico)", Studi Senesi, LiI, Siena, I938. La satisdatio era el nombre otorgado a la stipulatio (negocio verbal solemne, caracterizado, a gandes rasgos, por el intercambio de pregunta y respuesta en torno a un verbo típico; por ejemplo, el promisor preguntaba: spondes? Y el promitente respondía: spondo. Con lo cual se perefeccionaba el nacimiento de una obligación verbal), con intervención de garantes; a este respecto cfr. Marrone, M., Istituzioni di diritto romano, Palumbo, 2006, 454.

47 Roussier, J., "Satisfacere", en Studi in onore di Pietro di Francisci, II, 1956.

48 Cruz, Da "solutio", cit.

49 García del Corral, Cuerpo del derecho civil romano, t. I, cit., 237.

50 García del Corral, Cuerpo del derecho civil romano, t. I, cit., 522. 
Los textos, si bien están contextualizados con la satisdatio ${ }^{5 \mathrm{I}}$, nos resultan del todo pertinentes en este punto por la noción de satisfacere que introducen.

En el primero de ellos Gayo nos dice que con satisfacere se indica el acto de cumplir en favor de otro con aquello que desea (satisfacere dicimur ei, cuius desiderium implemus). De manera que, respecto de las relaciones obligatorias, satisfactio representa el hecho de ejecutar una conducta que repercuta en el agrado del acreedor, quien considera que sus intereses han sido contentados. Se trata, por lo tanto, de una conducta dirigida a llenar las expectativas que legítimamente alberga el acreedor.

En el segundo texto, Pomponio, comentando la obra de Sabino, dice que ha satisfecho quien ha ejecutado aquello respecto de lo cual el acreedor había manifestado darse por bien servido (quia id, quo quis contentus erat, ei praestabatur, satisfieri dictum est). Con lo que se reitera la satisfactio como un término que decribe tanto la acción como el efecto de alcanzar un estado de contentamiento del acreedor.

Si bien los dos fragmentos fijan una relación entre satisfactio y satisdatio, no por ello puede sostenerse que existe entre ellos una identidad $5^{2}$, sino más bien una relación de género a especie que es aún más notoria en el segundo de los textos que estamos analizando ahora.

Así, al poner en contexto el $\$ 3$ de D. 45, I, 5 con el parágrafo anterior, podemos ver que este último define el término satisdatio ${ }^{53}$ y que, a continuación, en el parágrafo tercero el jurista busca evidenciar que esta puede ser comprendida como una satisfactio (Satis autem accipere dictum est eodem modo, quo satis facere). Con lo cual no se puede decir que los dos conceptos sean la misma cosa, pues, evidentemente, ya se definió antes lo que es una satisdatio, para a continuación decir qué es una satisfactio. Es así evidente que entre ambos conceptos no hay identidad, sino que la satidatio puede ser considerada también una satisfactio porque la figura permite contentar al acreedor.

Satisfactio es, entonces, un concepto objetivo que indica, dentro del contexto obligatorio, una conducta del deudor dirigida a llenar las expectativas del acreedor. De ahí que, en general, la doctrina sostenga que con este concepto pueden describirse varios niveles de satisfacción, pudiendo abarcar el cumplimiento como acto que mejor satisface al acreedor, como así también otros mecanismos de contentamiento, en especial, el otorgamiento de garantías.

5 I El primero según la palingenesia de Lenel pertenece, dentro del libro v, al título denominado de satisdationis. El segundo es precedido por un parágrafo dedicado a definir la satisdatio.

52 Brasiello, "Satisfactio", cit.

53 D. 45, I,5 $\$ 2$ Satis acceptio est stipulatio, quae ita obligat promissorem, ut adpromissores quoque ab eo accipiantur, id est qui idem promittunt. 


\section{B. La noción de satisfactio en sentido estricto se identifica con el reforzamiento del crédito mediante el otorgamiento de garantías}

Resulta importante aclarar que la doctrina ${ }^{54}$, al atribuir un significado específico a satisfactio, ha sido algo arbitraria, puesto que los textos que vinculan este concepto con el de garantía no son tajantes y, al contrario, no permiten aclarar si la noción de satisfactio abarca todos los tipos de garantías; si otros mecanismos que puedan contentar al acreedor podrían ser abarcados por esta noción; e, incluso, si realmente exista una relación de identidad entre satisfactio y garantía.

Puestas de presente las dificultades en torno a este concepto, resulta necesario analizar aquellas fuentes del derecho romano de las cuales la doctrina ha concluido la existencia de un significado de satisfactio relacionado con el otorgamiento de garantías.

En dichas fuentes se ha evidenciado la existencia de una alternativa satisfactiosolutio por virtud de la cual el término satisfactio adquiere un significado que la aleja de la solutio55 y que implicaría, como consecuencia, la existencia de un valor semántico más restringido. A fin de establecer dicho significado, los textos se han analizado $^{56}$ por medio de una agrupación de los mismos así: i. Casos en los que existe una cláusula satisfactoria establecida por un privado; ii. Casos en los que la satisfactio permite, al igual que el pago, la transferencia del dominio en la compraventa; y, iii. Casos en los que la cláusula satisfactoria está contenida en el edicto del pretor.

Dentro de este trabajo hemos seleccionado sólo algunos de estos fragmentos, pues no pretendemos calcar las obras de quienes han estudiado el tema, sino al contrario presentar sus principales conclusiones y, de ser posible, agregar algunas observaciones a las mismas.

\section{Casos en los que existe una cláusula satisfactoria establecida por un privado}

Empezaremos entonces por dos fragmentos del Digesto en los que la satisfactio aparece dispuesta en una cláusula privada. El primero de ellos corresponde a D. $40,7,39 \$$ I y su texto es el siguiente:

54 Brasiello, "Satisfactio", cit.; Roussier, "Satisfacere", cit.; Cruz, Da "solutio", cit.

55 Brasiello, "Satisfactio", cit., I2.

${ }_{56}$ Brasiello, "Satisfactio", cit., I 3; siguiendo la misma estructura, Roussier, "Satisfacere", cit., I $20-$ I39. 
Javoleno; Doctrina de las obras póstumas de Labeón, libro Iv. [...] \$ I.- "Sea libre Stico cuando se hubieran pagado mis deudas, ó se hubiere satisfecho a mis acreedores"; respondieron Labeón y Ofilio, que aunque hubiese quedado un heredero rico, no habrá de ser sin embargo libre Stico antes que los acreedores hubiesen recibido el dinero ó fianza, ó hubiesen obtenido caución de otro cualquier modo ${ }^{57}$.
IAVOLENUS libro quarto ex posterioribus Labeonis [...] I 'Stichus liber esto, quando aes alienum meum solutum creditoribusve meis satisfactum erit.' Quamvis heres locuples extitisset, tamen non prius Stichum liberum futurum, quam creditores pecuniam aut satis accepisent aliove quo modo sibi cavissent, Labeo Ofilius responderunt.

En el caso expuesto por el fragmento estamos frente a una cláusula testamentaria conforme a la cual la libertad del esclavo Estico se somete a la condición de que todas las deudas del difunto hayan sido pagadas (solutum) o a la de que se hubiere satisfecho a sus acreedores (creditoribusve meis satisfactum).

El problema jurídico que surge frente a esta disposición es el de saber si la condición anterior debe ser respetada aun en el caso de que los herederos cuenten con tanta suficiencia económica como para hacer frente a todo el pasivo del causante $5^{8}$. La solución dada por Labeón y Ofilio, según nos reporta el pasaje, es que en efecto la condición debe ser respetada también en esa hipótesis y que, con independencia de la situación económica de los herederos, el esclavo únicamente será libre cuando se paguen las deudas del difunto o se satisfaga a los acreedores (Quamvis beres locuples extitisset, tamen non prius Stichum liberum futurum, quam creditores pecuniam aut satis accepisent aliove quo modo sibi cavissent).

Según Brasiello59, cuando Labeón sostiene que los acreedores deben "pagar el dinero o dar satisfacción" (accipere pecuniam aut satis), está dando una respuesta precisa, que no conduce a un concepto genérico sino, evidentemente, específico, el cual se lograría concretar al conectar el fragmento en estudio con otros $\operatorname{tantos}^{60}$ en los que aparece mencionado satis accipere siempre vinculado a una satisdatio, razón por la cual concluye que, sin lugar a dudas, satis accipere es la

57 García del Corral, Cuerpo del derecho civil romano, t. III, cit., 272.

58 Como bien lo explica Brasiello, "Satisfactio", cit., I4: "En este caso Estico es un elemento patrimonial que con la manumisión viene a menos: esta debe, por lo tanto, estar subordinada a la satisfacción de los acreedores, quienes de otra manera se verían privados de un elemento patrimonial de la herencia".

59 Brasiello, "Satisfactio", cit., I3 ss.

60 Brasiello, "Satisfactio", cit., I 5, con cita de D. 5,3,29: "Ulpianus libro I5 ad edictum. Mercedes plane a colonis acceptae loco sunt fructuum. Operae quoque servorum in eadem erunt causa, qua sunt pensiones: item vecturae navium et iumentorum"; D. 46,8, I5: "Paulus libro I4 ad Plautium... Si autem in ius eum vocaverit et satis iudicio sistendi causa acceperit..."; D. 46,8,8: "Venonius libro I5 stipulationum $\$ 2$. Si quis a procuratore status controversiam patiatur, satis accipere debet a procuratore, ne impune saepius pro suo statu conveniretur et, si dominus venientesque ab eo personae ratum non habuerunt"; D. 44,3,4: "Iavolenus libro septimo epistularum. Si servus bereditarius aut eius, qui in hostium potestate sit, satis acceperit, continuo dies satisdationis cedere incipiet”. 
expresión que corresponde típicamente a la satisdatio. Por lo tanto, el contenido de la satisfactio se identifica y agota en la satisdatio.

Sin embargo, si se analiza la última frase del fragmento" ("ó hubiesen obtenido caución de otro cualquier modo”) puede notarse que se integra coherentemente con el resto del discurso, y permite ver que el jurista, al explicar en sus palabras el contenido de la disposición testamentaria, hace corresponder la expresión creditoribusve meis satisfactum ("ó se hubiere satisfecho a mis acreedores") con dos posibles actos: satis accipere y aliove quo modo sibi cavissent. Por lo que es más que claro que el contenido de satisfactio no se agota en la satisdatio, la cual constituye sólo una de sus manifestaciones, sino que hay más modos de contentar a los acreedores. En esto estamos de acuerdo con Roussier ${ }^{62}$.

Pasemos ahora al análisis de D. 33,2,30 pr.:

Javoleno; Doctrina de las obras póstumas de Labeón, libro II. La mujer legataria del usufructo hasta que se le garantice totalmente la dote, al darle garantía un heredero por su parte, aunque no lo hicieran los otros herederos, dice Labeón que deja de tener el usufructo por aquella parte; y que lo mismo ocurre si la mujer incurriera en mora para recibir la garantía ${ }^{63}$.
IAVOLENUS libro secundo ex posterioribus Labeonis. Cui usus fructus legatus esset, donec, ei totius dotis satisfieret, cum ei heres pro sua parte satis dedisset quamvis reliqui satis non darent, tamen pro ea parte usum fructum desinere habere mulierem ait Labeo: idem fieri et si per mulierem mora fieret, quo minus satis acciperet.

El texto describe el caso de un legado de usufructo ${ }^{64}$ hecho por el esposo testador en favor de su mujer supérstite. Dicho usufructo, según el testamento, durará hasta cuando ella reciba total satisfactio de la dote (totius dotis satisfieret). Frente a este supuesto de hecho surge el problema jurídico de establecer si la satisfactio otorgada por alguno o algunos de los herederos extingue proporcionalmente el usufructo en la medida de las cuotas parte correspondientes al heredero o here-

6I Brasiello, "Satisfactio", cit., I4, frente a la última parte del fragmento, aliove quo modo sibi cavissent, sostiene que es una agregación posterior, puesto que el cavere "tiene un contenido muy amplio, y el tercer miembro de la antítesis es introducido por un $v e$ ".

62 Roussier, "Satisfacere", cit., I45.

63 D’Ors, A.; Hernández, F.; Fuenteseca, P.; M. García y Burillo, J., El Digesto de Zustiniano, t. II, Pamplona, Arazandi, I968, 530.

64 El legado de usufructo es una antigua figura por la cual el marido garantizaba, en favor de su esposa no sometida a potestad (sine manu), una renta vitalicia en caso de morir antes que ella. De esta manera el pater familias lograba proteger a su cónyuge supérstite sin disminuir el patrimonio de sus herederos, quienes quedaban obligados a entregar los frutos de la cosa legada sin perder su propiedad. Para profundizar en lo relativo al surgimiento y desarrollo del derecho de usufructo en el derecho romano cfr., por todos, CARDIlli, R., La nozione giuridica di fructus, Salerno, Edizioni Scientifiche Italiane. 
deros que han cumplido con la disposición del causante. La respuesta de Labeón, según lo informa Javoleno, es afirmativa.

Brasiello sostiene que el texto es muy claro al identificar la satisfactio referida en la disposición de última voluntad con la constitución de una satisdatio, a la cual se hace referencia al final del texto con la diciente expresión satis accipere.

Para el mismo autor, con tal identificación de conceptos se evidencia cómo el otorgamiento de una garantía viene considerado suficientemente idóneo para producir, en el sentido más lato de la expresión ${ }^{6}$, la satisfacción de los intereses de la esposa sobreviviente y por lo tanto para extinguir, sin más, el usufructo.

Sin embargo, adhiriendo a las reflexiones de Roussier, no puede pensarse que para la mujer es igual recibir la restitución de la dote (cumplimiento, solutio) que una garantía personal respecto de la señalada restitución. Sin duda, ni Labeón ni Javoleno habrían pensado que cosa semejante pudiera tener lugar. En realidad, la mención a satisfactio dentro del texto debe ser entendida como susceptible de comprender la satisfacción más idónea de todas: el cumplimiento, sin que ello excluya que se atribuyan efectos para la extinción del usufructo con un contentamiento diferente ${ }^{66}$, como el otorgamiento de una garantía, valiéndose, por ejemplo, de una satisdatio.

Adicionalmente, resulta pertinente subrayar que el contenido del texto no da fundamento a la afirmación de Brasiello conforme a la cual el testador tenía en mente sólo una manera de otorgar garantía, puesto que el término satisfactio era tan claro y definido a nivel jurídico que resultaba ya sabido que se concreta en una satisdatio ${ }^{67}$.

Examinadas hasta aquí algunas pocas de las fuentes del derecho romano que contienen una cláusula privada satisfactoria, pasemos entonces a analizar un segundo grupo de fuentes el cual, según la clasificación que la doctrina ha hecho, corresponde a aquellos casos relacionados con la transferencia del dominio en la compraventa.

\section{Casos en los que la satisfactio permite, al igual que el pago, la transferencia del dominio en la compraventa}

Dentro de este grupo de fuentes hemos de hacer referencia en primer lugar a D. I $8, \mathrm{I}, 53$ :

65 Brasiello, "Satisfactio", cit., i6.

66 Roussier, "Satisfacere", cit., I 23 : "On peut donc retenir le témoignage du fr. zo de favolenus. Comme il n'est pas doutez que le paiement de la dot satisferait encore mieux la veuve, on peut admettre que la seule mention de la satisfactio au testement ouvre en réalité le chemin à l'alternative solutio-satisfactio, du moins quand l'accomplissement de l'un ou de l'autre de ces actes constitue la condition à l'évènement de laquelle est subordonée une conséquence juridique ou non juridique".

67 Roussier, "Satisfacere", cit., I 22 , nota 2. 
Gayo; Comentarios al Edicto provincial, libro xxviII. Para que la cosa se haga del comprador no hay diferencia entre que el precio haya sido pagado o se haya dado fiador de él. Lo que se dice del fiador ha de tomarse en sentido más amplio: si el vendedor ha recibido garantía del precio por cualquier razón, como por ejemplo, mediante novación de un nuevo deudor o por dación de prenda, será como si el precio hubiese sido pagado ${ }^{68}$.
GAIUS libro XXVIII ad edictum provinciale. $U t$ res emptoris fiat, nibil interest, utrum solutum sit pretium an eo nomine fideiussor datus sit. Quod autem de fideiussore diximus, plenius acceptum est, qualibet ratione si venditori de pretio satisfactum est, veluti expromissore aut pignore dato, proinde sit, ac si pretium solutum esset.

En este fragmento, Gayo sostiene que el dominio de la cosa vendida se consolida en cabeza del comprador bien cumpliendo con el pago del precio, bien mediante la constitución de un fideiussor o fiador. $\mathrm{Y}$ a continuación explica que la referencia al fiador ha de entenderse más ampliamente, por lo que se obtiene el mismo efecto por medio de la dación de un nuevo deudor o por medio de la constitución de una prenda (veluti expromissore aut pignore dato).

Es importante señalar que estamos delante de un fragmento que ha sido estudiado por la doctrina, fundamentalmente, en relación con el problema de la exigencia de pago para la transferencia del dominio por virtud de la compraventa $^{69}$. Teniendo en cuenta que se trata de un problema complejo y de extensión considerable, que supera los límites temáticos de esta investigación, haremos mención a él sólo para señalar que el asunto entra en relación con nuestro trabajo debido a que se ha sostenido que en derecho clásico existió una regla conforme a la cual, en materia de compraventa, se producía la transferencia del dominio una vez verificado el pago del precio o la satisfactio ${ }^{70}$.

Dicho lo anterior, hemos de retomar el análisis del texto. Así, Brasiello defiende, en coherencia con su teoría en la materia, la existencia de una alternativa solutio-satisfactio para la consolidación del dominio en el comprador ${ }^{71}$. Dicha alternativa en el caso de la compraventa revela una evolución en el sentido de que la satisfactio, si bien continuaba siendo un concepto concreto, sufrió una ampliación de su alcance para abarcar también la constitución de fideiussores ${ }^{72}$.

68 D’Ors, Hernández, Fuenteseca, García y Burillo, El Digesto de Fustiniano, t. i, cit., 666.

69 Un breve resumen sobre el statu quo de la doctrina en este punto se encuentra en Brasiello, "Satisfactio", cit., 22, nota I.

70 Brasiello, "Satisfactio", cit., 25, aclara que para él resulta dudoso si la regla en mención se exigía para la transferencia del dominio o sólo para el surgimiento de la obligación de garantía por evicción.

7 I O para el surgimiento de la obligación de garantía por evicción, aunque abiertamente deja sin responder cuál es el efecto que desde su postura se produciría; Brasiello, "Satisfactio", cit., 2 I ss.

72 Brasiello, "Satisfactio", cit., 2 I ss. 
Así las cosas, Brasiello defiende la genuinidad del texto hasta fideiussor datus fit 73 y considera agregación posterior la continuación del texto, puesto que para él el concepto clásico de satisfactio abarcó únicamente la satisdatio y, en materia de compraventa, la constitución de fideiussores.

Lo anterior como producto de una evolución que se remonta a las XII Tablas ${ }^{74}$, en cuyo contexto no existía, como tal, una obligación del comprador de pagar el precio ni una correspondiente del vendedor de transferir el dominio. Razón por la cual Brasiello sostiene que en el momento en que se producía el acto formal, se concluía también una sponsio independiente de la mancipatio, en la cual el mancipio accipiens se constituía como deudor, asumiéndose, contemporáneamente, un garante (o sea una satisdatio). Surgida la venta consensual, se tiene una promesa formal del comprador acompañada de aquella de un garante; y finalmente la cosa habría de simplificarse, con la mera asunción de un fideiussor ${ }^{75}$.

Roussier, frente a esta interpretación, considera que en realidad nada se opone a creer que para Gayo la satisfactio pueda ser entendida más ampliamente y, por lo tanto, abarque el otorgamiento tanto de garantías personales como reales.

Para nosotros resulta artificiosa la conclusión de Brasiello según la cual la mención a la prenda y al expromissor es posterior a Gayo ${ }^{76}$. No obstante, sí es cierto que este mencionó la constitución de fideiussores, para luego defender, por esta vía, la idea de una identificación de la satisfactio con la fideiusso y cerrar allí el alcance del concepto.

Brasiello, "Satisfactio", cit., 30.

74 Brasiello, "Satisfactio", cit., 32, arriba a dicha conclusión valiéndose del contenido de I. 2, I,4I : "Mas si en verdad fueren entregados por causa de donación, o de dote, o por otra cualquiera, sin duda quedan transferidos: mas las cosas vendidas y entregadas no se adquieren para el comprador de otro modo, que si este hubiere pagado el precio al vendedor, o de otra manera le hubiere satisfecho, como por ejemplo, habiéndole dado un pagador o una prenda. Lo que se halla en verdad establecido por la ley de las Doce Tablas, pero que con razón se dice que se hace también por derecho de gentes, esto es, por derecho natural. Mas si el que vendió hubiere seguido la fe del comprador, se ha de decir, que la cosa se hace inmediatamente del comprador".

75 Brasiello, "Satisfactio", cit., 33 .

76 Nuevo deudor que entra a sustituir al existente, dando lugar a una novación subjetiva de la obligación. Roussier, "Satisfacere", cit., I47, I 54 ss. En lo que hace al expromissor y al problema de si podía ser o no abarcado por el concepto clásico de satisfactio, Roussier sostiene que si se analiza la figura desde el punto de vista del efecto que produce resulta incontestable que "la extinción de la deuda del comprador mediante una novación puede ser considerada como un equivalente del pago".

Adicionalmente, y más allá de si en concreto con una novación por cambio de deudor se pueda consolidar el dominio en cabeza del comprador, desde su perspectiva la expromissio sí puede ser comprendida como un modo satisfactorio, en especial si se comprende que la satisfactio es fundamentalmente un acto jurídico cuyo objeto es disipar en el acreedor cualquier inquietud sobre sus posibilidades de obtener el cumplimiento de la obligación. Vista así, la expromissio tendría espacio dentro de la satisfactio, ya que un cambio de deudor podría tener por objeto y por efecto reforzar las seguridades del acreedor, en especial porque con ella no se altera la naturaleza del debitum ni se disminuye el derecho del acreedor a exigir incluso forzadamente el cumplimiento de su crédito. 
Así las cosas, puede notarse cómo D. i 8, I,53 describe el alcance de la satisfactio como susceptible de abarcar el otorgamiento de garantías reales e incluso la novación por cambio de deudor (expromissio), y permite ver que el elemento fundamental que identifica el término satisfactio es su aptitud para actuar como refuerzo de la consecución del cumplimiento por medio de mecanismos que garantizan al acreedor la satisfacción de sus intereses.

Continuemos nuestro análisis con aquellas fuentes a partir de las cuales la doctrina ha pretendido determinar el contenido de satisfactio, y pasemos entonces al tercer y último grupo de casos, es decir, aquellos en los que la consecución de un determinado efecto está condicionada por una alternativa solutio-satisfactio prevista en el Edicto.

\section{Casos en los que la consecución de un determinado efecto jurídico está condicionada por una alternativa solutio-satisfactio prevista en el Edicto}

Dentro de este grupo escogimos examinar el contenido de D. I 3,7,9 $\$ 3$ :

Ulpiano; Comentarios al Edicto, libro xxviII. Para que nazca la acción pignoraticia debe haberse pagado toda deuda, o haberse satisfecho por tal motivo. Entendemos por haberse satisfecho, de cualquier modo que haya aceptado el acreedor, aunque no se haya pagado: nace la acción pignoraticia ya se garantice con otras prendas para dejar la que se dio, ya sea mediante fianza, por novación de nuevo deudor, a cambio de un precio o por mera convención. $\mathrm{Y}$, en principio, hay que decir que cuando el acreedor aceptó dejar la prenda, se entiende "haberse satisfecho", siempre que se le dé caución como él quiso, aunque haya sido engañado con ello ${ }^{77}$.
ULPIANUS libro XXVIII ad Edictum. Omnis pecunia exsoluta esse debet aut eo nomine satisfactum esse, ut nascatur pignoraticia actio. Satisfactum autem accipimus, quemadmodum voluit creditor, licet non sit solutum: sive aliis pignoribus sibi caveri voluit, ut ab boc recedat, sive fideiussoribus sive reo dato sive pretio aliquo vel nuda conventione, nascitur pignoraticia actio. Et generaliter dicendum erit, quotiens recedere voluit creditor a pignore, videri ei satisfactum, si ut ipse voluit sibi cavit, licet in hoc deceptus sit.

En el texto, Ulpiano, comentando el Edicto y, en concreto, comentando los presupuestos necesarios para el ejercicio de la actio pignoraticia $^{78}$, señala que para ello

77 D’Ors, Hernández, Fuenteseca, García y Burillo, El Digesto de fustiniano, t. I, cit., 530.

78 Acción contenida en el edicto del pretor para tutelar al deudor prendario contra el acreedor prendario que "habiendo recibido una cosa en prenda para la garantía de su crédito, una vez extinguido el crédito no la hubiese restituido. La acción, se repite, era in personam, muy distinta por lo tanto de la actio pignoraticia in rem o serviana, que era para tutelar el derecho real de 
es necesario el cumplimiento o en su defecto proveer una satisfactio (Omnis pecunia exsoluta esse debet aut eo nomine satisfactum esse, ut nascatur pignoraticia actio). Y a continuación describe cuáles hipótesis distintas del cumplimiento podrían abrir la puerta al uso de la actio pignoraticia. Allí incluye la sustitución de la prenda actual con una cosa diferente; la constitución de una fideiusso; la novación subjetiva; la negociación de un precio; e incluso la mera convención (sive aliis pignoribus sibi caveri voluit, ut ab hoc recedat, sive fideiussoribus sive reo dato sive pretio aliquo vel nuda conventione, nascitur pignoraticia actio). Finalmente, el jurista, usando la noción de cautio, regresa a su punto de partida y explica que cuandoquiera que se constituya en favor del acreedor, en términos por él libremente aceptados y deseados, una garantía del pago de su crédito, habrá una satisfactio.

Interesante resulta el análisis sobre la posible intervención que pudo haber sufrido aquella parte del fragmento que incluye la remisión de la deuda (nuda conventio) dentro de la categoría de satisfactio 79 . En primer lugar, se destaca cómo la nuda conventio no puede compararse con las demás figuras enlistadas dentro del texto, puesto que si bien la satisfactio presupone la participación del acreedor -ya que finalmente es él quien la acepta-, ella proviene fundamentalmente de una conducta del deudor, pues es este último quien despliega los actos necesarios para reforzar las seguridades del acreedor frente a la obtención de su crédito. Dicha participación esencial no tiene lugar en el caso de una remisión, la cual emana básicamente de un acto de mera liberalidad del acreedor.

En segundo lugar, las incompatibilidades entre la satisfactio y la remisión pueden notarse desde la perspectiva de las exigencias prácticas que dieron origen a diversos mecanismos de tutela. Así, en caso de acuerdo entre acreedor y deudor para liberar la prenda a cambio de otra garantía, surgió la necesidad de dotar al deudor de la tutela idónea para recuperar la cosa prendada en caso de resistencia del acreedor. Por esta razón se agregó a la fórmula de la actio pignoraticia la hipótesis de satisfactio. Mientras que la remisión, por su parte, era un simple pacto, no siendo apta para legitimar al deudor para intentar la acción ${ }^{8 \circ}$.

En tercer lugar ${ }^{8 \mathrm{I}}$, se duda de la pertenencia original al fragmento de la hipótesis de la nuda conventio, debido a que con ello se introduce una incoherencia sustancial en el término satisfactio, el cual, por esta vía, quedaría sometido al mero

prenda y que se concedía al acreedor prendario contra el poseedor de la cosa pignorada": Marrone, Istituzioni, cit., 447.

79 Grosso, "Remissione del pegno e 'satisfactio", cit., 355.

8o Marrone, Istituzioni, cit., 87: en Roma, "algunos hechos daban lugar a pretensiones tuteladas con actiones y algunos hechos daban lugar a pretensiones tuteladas solamente con exceptiones"; 485: "los pactos puros y simples, generalmente llamados nuda pacta, que no era posible encuadrar en el esquema de algún contrato consensual. A estos fue siempre negada en línea de principio en el derecho romano eficacia constitutiva de obligaciones; y fueron tutelados con excepciones"; la remisión del débito, como se ha dicho ya, es un nuda pacta.

8I Grosso, "Remissione del pegno e 'satisfactio”, cit., 362. 
arbitrio del acreedor y reducido, en consecuencia, a un mero estado subjetivo: la renuncia a la prenda por parte del acreedor.

Finalmente, se descarta la pertenencia original de la remisión al texto, por el hecho de que ningún jurista romano la incluyó en la satisfactio, como requisito negativo para el ejercicio de la actio serviana.

De esta manera, podemos notar que el contenido de este pasaje del Digesto nos reitera la pluralidad de los modos satisfactorios, la cual no redunda en la ausencia de un concepto objetivo y concreto de satisfactio en el cual pudiera entrar de manera indiferente cualquier causa de extinción de una obligación.

$\mathrm{Al}$ contrario, estamos de frente a un concepto que en la época clásica abarcó aquellos actos jurídicos susceptibles de respaldar la obtención de un cumplimiento sin pretender sustituirlo, pues, debemos enfatizarlo, la alternativa que nos presentan los pasajes analizados no es una alternativa conforme a la cual el deudor "cumple" bien con solutio, bien con satisfactio, como si estuviéramos en presencia de una obligación alternativa, sino que al contrario se trata de una alternativa que desempeña su rol cuando un determinado efecto jurídico (la liberación del esclavo Estico; la restitución de la dote; la transferencia del dominio; o el ejercicio de una acción) está condicionado a que se produzca una solutio o una satisfactio ${ }^{82}$. Tal alternativa fue admitida, desde nuestro criterio, por razones de índole práctica, pues como la satisfactio reforzaba la posibilidad de obtener el cumplimiento, podían alcanzarse otros efectos jurídicos desde antes del efectivo cumplimiento, sin que de esta manera se viera disminuida la posición del acreedor.

Podemos dar entonces por terminado el recorrido que hemos hecho para determinar el alcance del término satisfactio en la época clásica. Hemos así llegado a convencernos de que el concepto abarcó una pluralidad de figuras, pero no de manera indiscriminada, sino sólo respecto de aquellos actos jurídicos que en el contexto de las relaciones obligatorias desempeñaron un rol de refuerzo y protección de las expectativas del acreedor. Razón por la cual dentro de ella tuvieron cabida la satisdatio, la fideiusso, la prenda, la expromissio. Todas ellas caracterizadas por desempeñar frente al cumplimiento exacto una función clara: garantizarlo y protegerlo de manera reforzada.

\section{Conclusiones}

- El uso del término solutio sufrió una transformación durante la transición de los periodos arcaico y clásico del derecho romano, que consistió en una evolución por la cual solutio dejó de identificar el acto solemne de liberación de un estado de responsabilidad, para indicar la conducta sustancial de cumplimiento ejecutada por el deudor en favor del acreedor.

82 En ello estamos completamente de acuerdo con Roussier, "Satisfacere", cit., I 29. 
- En las fuentes del derecho romano conviven testimonios que reflejan la existencia de dos acepciones asociadas al término solutio. Por una parte, pueden encontrarse textos que testimonian que este concepto se usaba para indicar en general la extinción de las obligaciones, y por otra parte encontramos textos en los que solutio, o alguna de las formas verbales de solvere, permitía identificar de manera restringida la descripción del cumplimiento de la prestación debida.

- En la indagación sobre el contenido y alcance del término satisfactio pudimos concluir que las fuentes romanas atestiguan que a esta figura se le reconoció en determinadas circunstancias la capacidad de producir algunos de los mismos efectos que se reconocieron a la solutio, de ahí la pertinencia de su estudio.

- Satisfactio en sentido lato, describe tanto la acción como el efecto de alcanzar un estado de contentamiento del acreedor.

- Despejar el significado de la alternativa solutio-satisfactio constituyó uno de los objetivos del análisis exegético presentado, pues se pretendía aislar, por esta vía, la órbita de la voz latina solutio. Lo anterior permitió discriminar un ámbito conceptual para nuestra investigación, ya que se comprende de esta manera que solutio describe en sentido estricto la conducta por la cual se desarrolla a cabalidad el contenido de la obligación para alcanzar no sólo la extinción de la obligación cumplida sino también la realización de la función que le era propia. Como resultado fue posible comprender que el cumplimiento (solutio) de las obligaciones en derecho romano clásico no debe confundirse con el término satisfactio, el cual, si bien resulta cercano al primero, describe, en sentido estricto, el otorgamiento de garantías.

- El contenido de D. I $3,7,9 \$ 3$ confirma que la satisfactio fue un concepto que abarcó varias modalidades, tales como el reemplazo de la cosa prendada por otra, la constitución de una fideiusso, la novación subjetiva, la negociación de un precio, e incluso la mera convención.

- Tal y como se dedujo del análisis de casos en los que existe una cláusula satisfactoria establecida por un privado; de casos en los que la satisfactio permite, al igual que el pago, la transferencia del dominio en la compraventa, y de casos en los que la cláusula satisfactoria está contenida en el edicto, satisfactio en sentido estricto se identifica con el otorgamiento de garantías en favor del acreedor. 


\section{Bibliografía}

\section{Doctrina}

Ankum, H. "La forma dell'acceptilatio nella realtà giuridica di Roma nel periodo

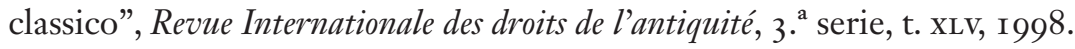

Arangio-Ruiz, V. Istituzioni di diritto romano, I4. ${ }^{\text {a }}$ ed., Napoli, Jovene, I 978.

Betтi, E. "De la interpretación del derecho”, SDHI, xxxıI, I966.

Betti, E. "Recensión a Cruz, Da "solutio". Terminología, conceito e características, e análise de vários institutos afins”, en SDHI. 29 (I963).

Biondi, B. "Lex e ius" en Revue Internationale des droits de l'antiquité, 3. serie, t. XII, I965.

Biondi, B. Istituzioni di diritto romano, 4 . $^{\text {a }}$ ed., Milano, Giuffrè, I 972.

Branca, G. “Adempimento”, E.D., I, Milano, Giuffrè.

Brasiello, U. "Satisfactio (preliminari e diritto classico)", Studi Senesi, LII, Siena, I938.

Cardilli, R. "Lege XII tabularum praeposita iungitur interpretatio", en Estudios de derecho civil. Obligaciones y contratos, Libro homenaje a Fernando Hinestrosa 40 años de Rectoría I963-2003, Bogotá, Universidad Externado de Colombia, 2003 .

Corbino, A. "Il rituale della mancipatio nelle descrizioni di Gaio", sDHI, XLII, I976.

Corpus Iuris Civilis. Digesta, Mommsen-Krueger, vol i. Hildesheim, Weidmann, I993.

Cruz, S. Da "solutio". Terminologia, conceito e características, e análise de vários institutos afins, I. Épocas arcaicas y clasicas, Coimbra, I 962

Cruz, S. Da solutio, II- I Época post clássica occidental solutio $e$ Vulgarrecht, Coimbra, I974.

D’Ors, A., Hernández, F., Fuenteseca, P., García, M. y Burillo, J., El Digesto de Fustiniano, t. II, Pamplona, Aranzadi, I968, 
De Martino, F. "Riforme del Iv secolo a.C.”, Bulletino dell'Istituto di diritto romano Vittorio Scialoja, vol. LxxviII, I975.

Fasolino, F. "Note in tema di solutio ante diem: tempo e valore económico della prestazione nella riflessione dei prudentes", Fides Humanitas Ius, Studi in Onore di L. Labruna, vol. III.

Fiori, R., "Contrahere e solvere obligationem in Q. Mucio Scevola”, en Fides Humanitas Ius, Studi in onore di Luigi Labruna, III, Napoli, Editoriale Scientifica, 2007.

García Garrido, M. "Recensión a Cruz, Da 'solutio'. Terminología, conceito e características, e análise de vários institutos afins”, AHDE 32 (I962).

García del Corral, I., Cuerpo del derecho civil romano, t. III, Barcelona, Lex Nova, I 889

Grosso, G., "Remissione del pegno e 'satisfactio", Atti della Reale Accademia delle Scineze di Torino LXV (I930), recopilado en Scritti storico giuridici, t. III, Diritto privato. Persone obbligazioni successioni, Torino, Giappichelli, $200 \mathrm{I}$.

Grosso, G., Lezioni di storia del diritto romano, 5. ${ }^{\text {a }}$ ed., Torino, Giappichelli, I 965 .

Lenel, O., Palingenesia Iuris Civilis, vol. I. Graz: Akademische Druck - U. Verlangsanstalt, i960.

Magdelain, A., "L'acte per aes et libram et l'auctoritas", en Revue Internationale des droits de l'antiquité, t. XXVIII, I98I.

Marrone, M. Istituzioni di diritto romano, Palumbo, 2006

Melillo, G. In solutum dare. Contenuto e dottrine negoziali nell'adempimento inesatto, Napoli, Jovene, I970.

Miguel, J. “Recensión a Cruz, Da 'solutio'. Terminología, conceito e características, e análise de vários institutos afins”, ZSS. 81, I964.

Mitteis, L., Index interpolationum. A cura di Ernest Levy e Ernest Rabel, t. I, Weimar: Hermann Böhlaus Nachfolger, I929.

NARDi, E. Radiografia dell'aliud pro alio consentente creditore in solutum dare en St. Donatuti, 2 , I973. 
Pacchioni, G., Corso di diritto romano, vol. III, Torino, Utet, I922

Periñán, B., "forum debitoris" y "locus solutionis", en SDHI, 67 (200I).

Roussier, J., "Satisfacere", en Studi in onore di Pietro di Francisci, v. II, I956.

Saccoccio, A., Aliud pro alio consentiente creditore in solutum dare, Milano, Giuffrè, 2008.

Sansón Rodríguez, M. "La buena fe en el ejercicio de los derechos y en el cumplimiento de las obligaciones", en Il ruolo della buona fede oggettiva nell'esperienza giuridica storica e contemporanea, vol. III.

Schipani, S., Iustiniani augusti digesta seu pandectae, v. III, Milán, Giuffre, 2007,

Schulz, F., Storia della giurisprudenza romana, trad. Guglielmo Nocera, Firenze, Sansoni, I968.

SolazzI, S., L'estinzione delle obbligazioni nel diritto romano, 2. ${ }^{\mathrm{a}}$ ed., Napoli, Jovene, I 935 .

Talamanca, M., Istituzioni di diritto romano, Milano, Giuffrè, I990.

Tomulesco, C. St., "Quelques petites études de droit romain”, en Bulletino dell'Istituto di diritto romano Vittorio Scialoja, vol. LxxxII, I979.

\section{Fuentes jurídicas de derecho romano}

Digesto de justiniano (D.)

\begin{tabular}{|c|c|c|c|c|}
\hline $2,8, \mathrm{I}$ & $\mathrm{I} 3,3,4$ & I9, I, I I ,2 & $32,4 \mathrm{I}, 7$ & $45, \mathrm{I}, 6 \mathrm{O}$ \\
\hline $2, \mathrm{I} 3,4,5$ & $\mathrm{I} 3,3, \mathrm{IO}$ & $2 \mathrm{O}, \mathrm{I}, \mathrm{I} 3,4$ & $33, \mathrm{I}, \mathrm{I}$ & $46,3,28$ \\
\hline $3,3,54$ & $\mathrm{I} 3,4,2$ & 20,6,6 pr. & $33,2,30 \mathrm{pr}$ & $46,3,49$ \\
\hline $4,3,28$ & I $3,7,9,3$ & $20,6,6, \mathrm{I}$ & $3^{8, \mathrm{I}, 2 \mathrm{I}}$ & $46,3,54$ \\
\hline $5, \mathrm{I}, \mathrm{I} 9$ & I $3,7,9,4$ & $20,6,6,2$ & $40,7,39, \mathrm{I}$ & $46,3,6$ I \\
\hline $5, \mathrm{I}, 65$ & I $3,7,9,5$ & $20,6,5,2$ & $40,7,39,2$ & $46,3,80$ \\
\hline $5, \mathrm{I}, \mathrm{I} 38$ & $\mathrm{I} 3,7, \mathrm{IO}$ & $20,6, \mathrm{I} 4$ & $4^{2}, 5, I-3$ & $46,8,8,2$ \\
\hline $5, \mathrm{I}, 38$ & $\mathrm{I} 3, \mathrm{I} 7, \mathrm{IO}$ & $2 \mathrm{I}, \mathrm{I}, \mathrm{I} 8, \mathrm{I}$ & $43,24,6$ & 46,8, I 5 \\
\hline $5,3,3$ pr. & $\mathrm{I} 4,4,5, \mathrm{I} 8$ & $24,3,24,2$ & $43,32, \mathrm{I}$ pr. & $47, \mathrm{IO}, \mathrm{I} 7,6$ \\
\hline
\end{tabular}




$\begin{array}{lllll}5,3,28 & \text { I 6, 3, I 2, I } & 25,3,8 & 45, \mathrm{I}, \mathrm{I} 37,2 & 50, \mathrm{I} 6, \mathrm{I} 76 \\ 5,3,29 & \text { I 8, I, I9 } & 30,26, \mathrm{I} & 45, \mathrm{I}, 5,2 & 50, \mathrm{I} 6,47 \\ \text { I 2, I,2 } & \text { I 8, I, 53 } & 30,47, \mathrm{pr} . & 45, \mathrm{I}, 5,3 & \end{array}$

Instituciones de Gayo (Gai.)

$\begin{array}{ll}3, \mathrm{I} 23 & 3, \mathrm{I} 73 \\ 3, \mathrm{I} 25 & 3, \mathrm{I} 74 \\ 3, \mathrm{I} 68 & 4, \mathrm{I} 69\end{array}$

Instituciones de Justiniano (I.)

$2, \mathrm{I}, 4 \mathrm{I}$ 